\title{
Effects of Factors That Influence Out-of-Plane Lateral-Torsional Buckling on Freestanding Circular Arches
}

\author{
Emmanuel-Peters Teke Tebo $(\mathbb{D}$, Leonard Masu $(\mathbb{D}$, and Patrick Nziu \\ Department of Mechanical Engineering, Vaal University of Technology, Andries Potgieter Blvd, Vanderbijlpark 1900, Gauteng, \\ South Africa \\ Correspondence should be addressed to Emmanuel-Peters Teke Tebo; emmapeters007@gmail.com
}

Received 11 December 2019; Revised 26 February 2020; Accepted 4 March 2020; Published 1 May 2020

Academic Editor: Pierre Yves Manach

Copyright ( $) 2020$ Emmanuel-Peters Teke Tebo et al. This is an open access article distributed under the Creative Commons Attribution License, which permits unrestricted use, distribution, and reproduction in any medium, provided the original work is properly cited.

\begin{abstract}
This paper presents the effects of the several factors that influence lateral-torsional buckling on freestanding circular arches. The studied factors that attribute to the effects of lateral-torsional buckling include cross section type, included angle, slender ratio, imperfection, loading, and boundary conditions. From the reviewed studies, the misrepresentation of these factors to a certain extent may yield inaccurate results. Several studies and design codes have proposed different solutions to account for these factors in designs against lateral-torsional buckling for some structural elements. However, there were no studies reported on the out-ofplane lateral-torsional buckling of fixed circular arches made of structural aluminum channel sections subjected to central concentrated load. Therefore, there is a need for further research on the lateral-torsional buckling real behavior of fixed circular arches of structural aluminum channels.
\end{abstract}

\section{Introduction}

In this review study, an arch is referred to as a beam curved in elevation and loaded in its plane, with its supports prevented from moving together or apart [1]. In case of any displacement at one or both supports, such a member is referred to as "curved beam" ([2]:2). Arches can be referred to as shallow or deep arches depending on the included angle [3]. The steel and aluminum "Al" alloys members are the most commonly used materials for arches in structural applications ([4]:762). These members' profiles are of double symmetric or monosymmetric sections. Cross sections whose center of gravity (C) and shear center (S) coincide are known as double symmetric, whereas cross sections whose center of gravity and shear center do not coincide are referred to as the monosymmetric sections [5]. Based on the profile type, some of these members that are applied in structures as load-bearing skeleton may experience buckling stability problems.

The buckling instabilities on steel and $\mathrm{Al}$ alloys with open thin-walled double and monosymmetric sections acting as arches have been extensively researched [4]. High interest in steel arches has produced outputs that have led to design guidelines being developed and incorporated into design standards and code of practice [1]. However, the reviewed literature cannot confirm the same phenomenon in $\mathrm{Al}$ alloys. Studies on the instability of open thin-walled monosymmetric sections are few. Despite the application of these sections in structure, especially in areas where high performance with minimum weight is required [6], both the double and monosymmetric sections used as a load-bearing skeleton in structures are liable to experience instability caused by the lateral-torsional buckling “LTB" [2].

The LTB which is mostly influenced by transverse loading is considered as a common cause of instability in unrestraint open thin-walled sections $[7,8]$. This limit state stability problem occurs when the compression flange edge yields. The yielding of the compression flange causes inplane bending on members' strong axis to change to lateral displacement and twisting $[9,10]$. The LTB can be characterized under in-plane or out-of-plane buckling ([4]:762). 
The fundamental studies of LTB behavior go as far back as 1899 [8]. The study by Timoshenko and Gere [11] is considered to be the first to have proposed closed-form solutions for arches of double symmetric sections [2]. On the other hand, the study by Vlasov [12] is considered to be the first to present closed-form solutions for arches of monosymmetric I-sections. Several studies based on analytical, numerical, and experimental methods have been carried out on the elastic and inelastic LTB behavior of freestanding arches. However, most studies have reported on elastic behavior as compared to the inelastic behavior of arches. In both elastic and inelastic analyses, researchers looked at some common factors that significantly influence LTB on arches. These factors are imperfections (material nonlinearity, initial geometric imperfection, and residual stresses), cross section (double and monosymmetric), included angle (shallow, deep), slender ratio (slenderness), boundary conditions (pinned and fixed ends), and loading conditions such as uniform, radial, and point loads [13].

Several studies have reported on the elastic LTB of pinned arches/curved beams in uniform compression and bending. From the reported studies, some of the analytical studies include those by Timoshenko and Gere [11], Vlasov [12], Yoo and Pfeiffer [14], Rajasekaran and Ramm [15], Papangelis and Trahair [16], Yang and Kuo [17, 18], Rajasekaran and Padmanabhan [19], Yang et al. [20], Trahair [21], Kang and Yoo [22], Bradford et al. [23], Pi et al. [24], Bradford et al. [25, 26], Yang et al. [27], and Pi and Bradford [28]. Some discrepancies exist among the reported studies. Most of these discrepancies are linked with the methods used, that is, the use of complete analytical methods or numerical methods alongside analytical methods to propose closed-form solutions. Thus, subsequent studies focused on rectifying these methods. The study by Bradford and Pi [26] is considered to have provided the most refined solution among others. A recent study by $\mathrm{Pi}$ and Bradford [28] proposed solutions for pinned arches with rotational restraints.

The LTB behavior of fixed arches under uniform compression or bending differs from pinned arches [4]. Pi and Bradford [29, 30], Bradford and Pi [31], and Dou et al. [32] studied the LTB of fixed circular arches under uniform compression and bending. The studies assumed the prebuckling stress state as trivial, so they are simple.

A more complex situation develops in arches subjected to central concentrated load "CCL." This complexity arises because the applied load develops combined axial compressive and bending moment action in the arch [33]. The joint action is nonuniform with complex distribution patterns. Due to this complex nature, analytical studies on such arches are rare, especially for fixed arches. Papangelis and Trahair [34], Pi et al. [3], Pi and Bradford [35], Liu et al. [36], and Lu et al. [37] studied the elastic LTB of pinned arches subjected to CCL. These studies used numerical methods to confirm proposed solutions that focused on double symmetric sections. However, the structural behavior of such members is different from monosymmetric sections such as channels. This occurrence is due to the position of the shear center and center of gravity ([38]:6).

In practice, most arches' ends are out-of-plane fixed. The mode of LTB shape for such arches is considered more complicated than pinned arches [33]. This complexity in the analytical solutions has made researchers find recourse in numerical methods such as finite element analysis (FEA). Thus, very few analytical studies have been reported. As a result, few theoretical studies have been reported on out-ofplane buckling of fixed arches subjected to CCL. Yang et al. [20], Pi and Trahair [39], Kang and Bert [40], Pi and Bradford [35], Pi et al. [41], and Pi et al. [42] studied the LTB of fixed arches under a CCL by making recourse to the numerical methods and focused on I-sections. Liu et al.'s [33] study proposed an analytical elastic LTB load for fixed arches subjected to CCL. The study focused on double symmetric sections and ignored the effects of the imperfections. These effects are considered important for real LTB behavior of arches [1].

Experimental studies are known to provide the true LTB behavior of arches. Using experimental studies, Papangelis and Trahair [43], La Poutré, [2], Liu et al. [44], Dou et al. [45], Pi et al. [42], and Lu et al. [37] investigated the elastic and inelastic LTB behavior of arches. The authors used these studies to validate proposed analytical solutions and numerical results. Several experimental studies on the elastic and inelastic out-of-plane buckling of arches subjected to CCL, arbitrary load, or uniformly distributed load have been reported by La Poutré [2], Ziemian [4], Spoorenberg [1], and Guo et al. [46]. Among these reported studies, insufficient information still exists for the LTB stability and behavior fixed ends arches made from $\mathrm{Al}$ alloy channels. Also, there are no reported data on the influence the roll bending process has on imperfections when forming an arch from Al alloy channels, although the research by Spoorenberg [1] has shown the effects of roll bending process on imperfections in comparison to the imperfections in beams and columns.

Most studies have investigated the influence factors such as cross section, included angle, slenderness, end supports, loading, and imperfections have on the out-ofplane LTB of freestanding arches. Several research studies focused on the elastic analysis of double symmetric thinwalled sections. A fair argument in the trend may be due to the simplicity in their analysis as their shear center and center of gravity coincide. Also, from the perspective of load and boundary conditions regarding simplicity in analysis, researchers focused more on pinned arches subjected to uniform bending and compression. These conditions produce less complex buckling failure shape mode compared to fixed arches and arches subjected to CCL. In this regard, this review article focuses on out-ofplane LTB of thin-walled arches of both double and monosymmetric sections subjected to point loads. The aim is to investigate the effects of several factors on the LTB of freestanding circular arches. These factors include pin and fixed end supports, central concentrated load at different points, imperfections, included angles, and slenderness. 
Also, the review covers the different methods used by researchers to study LTB.

\section{Methods Used to Measure Buckling}

For decades, researchers have made use of the theoretical, experimental, and numerical methods to determine the buckling of structural members [4]. In engineering practices, these techniques have a common trend of implementation to analyze material applications. These techniques can be applied alternatively depending on the need, availability, and complexity of the problem [47]. The techniques have different submethods of applications based on different assumptions and the level of accuracy needed.

2.1. Theoretical Techniques. In buckling analysis, the theoretical techniques have played vital roles in different structural designs $[4,48,49]$. Theoretical techniques used in stability analysis of frames and single structural members are the $1^{\text {st }}$ - and $2^{\text {nd }}$-order analyses. The $1^{\text {st }}$ - and $2^{\text {nd }}$-order analyses are characterized into $1^{\text {st }}$ and $2^{\text {nd }}$-order elastic analysis and $1^{\text {st }}$ - and $2^{\text {nd }}$-order inelastic analysis. The aforementioned analyses characterizations are used by researchers to describe the elasticity, elastoplastic, and plasticity theories used in buckling analysis ([4]:693).

The $1^{\text {st }}$ - and $2^{\text {nd }}$-order analysis has been and is still used in different mathematical methods and principles to derive closed-form solutions for LTB. Some of the applied principles include the principle of virtual work [19], stationarity in the total potential or static equilibrium theory [23], and Euler Lagrange theory $([4,50]: 1033)$. These theoretical solutions are generally referred to as closed-form, exact, or analytical solutions [4]. The application of these theories by the traditional pen, paper, and hand calculator calculations is time-exhausting. Alternative use of computer software programs such as Mathcad, MATLAB, and Maple helps to save time by solving more complex differential and simultaneous equations and obtaining practical solutions. From all the theoretical solutions, the $2^{\text {nd }}$-order inelastic analysis is the most replicate of real buckling behavior. However, its inherent complexity makes such an analysis type be carried out through numerical techniques ([1]:9).

2.2. Numerical Techniques. Numerical methods are considered as approximate mathematical procedures [47]. These techniques are established for cases whereby no exact solution exists or intractable cases like solving simultaneous equations with many unknown variables, that is, 20 . The solutions generated using numerical methods are considered as approximate solutions [51]. Numerical methods may have limitations. Some of these limits include the software having a predesigned feature with less possibility of alterations to suit specific analysis needs. Also, there are a limited number of nodes in some cases, and the shape of the element cannot fully represent the exact particle range of the real member. Besides, some analyses may require immensely powerful computers to run. Nevertheless, these numerical methods along with the experimental methods are used to develop and validate stability equations [52].

Some numerical methods used in providing accurate elastic buckling solutions for open thin-walled members include differential quadrature method (DQM) [40], $\mathrm{C}^{0}$-type element [53], finite element analysis (FEA), numerical integration method/Newmark's method, finite strip analysis, finite difference, boundary element, and generalized beam theory ([4]:568). Based on the structural element and boundary and loading conditions, different numerical methods are suitable for different analyses. However, buckling analysis of beams, columns, and arches mostly involves the use of the traditional FEA, with the reason being that this numerical method is not limited to elastic or inelastic stability solutions but provides a wider range of application that includes inelastic analysis [54].

The finite element model (FEM) for numerical analyses is normally modeled in 2 dimensions (2D) or 3 dimensions (3D). The $2 \mathrm{D}$ is known to provide efficient analysis that is less accurate as compared to $3 \mathrm{D}$ that gives to a certain extent a real solution. Some FEA commercial software used for modeling 2D and 3D models for buckling stability analysis includes ABAQUS, ANSYS, ADINA, FUSION 360, SOLIDWORKS, COLBEAM, and PROKON $[4,55,56]$. The choice of software for application generally depends on availability, type of stability analysis to be performed, structural elements to be analyzed, and the level of accuracy needed ([4]:1033; [47]).

2.3. Experimental Techniques. The main difference between the experimental technique and the other aforementioned techniques is the use of prototype specimens for experimental testing to predict real behavior ([2]:23). This technique is considered costly due to the use of prototype specimens, equipment, and labor [47]. The flexural test is known as the most common stability test used for LTB behavior for arches [37]. This stability test is used to verify or develop design equations, that is, to establish how accurate the proposed numerical and theoretical solutions can predict real behavior ([4]:1013).

In the LTB test, the general test measurements include the loads and reactions using calibrated load cells, displacement, and distortion using linear variable displacements transducers (LVDTs) and strains using electrical resistance strain gauges. Examples of some LTB test setup used by researchers are shown in Figures 1 and 2. Similar flexural test setups were used by other researchers, the difference being on the end supports and loading.

\section{Lateral-Torsional Buckling}

The LTB behavior of freestanding circular arches is generally attributed to loading and boundary conditions [33], that is, end supports type (pinned or fixed) and load type (uniform compression and/or uniform bending, radial point load or transverse loading, and axial loading). Other parameters that are associated with the material type and cross section also influence LTB resistance [5], for example, material 


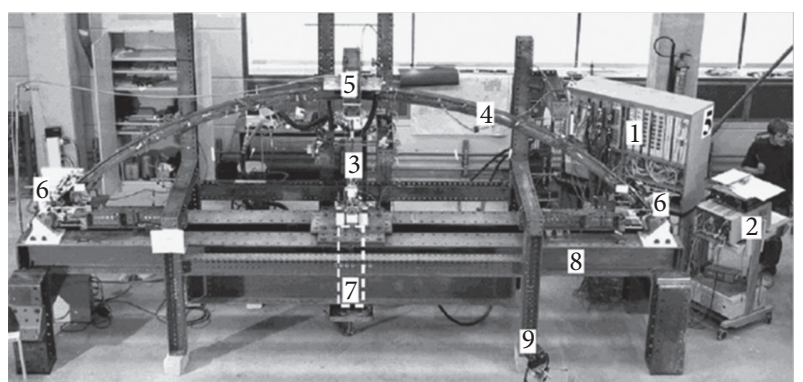

1. Data acquisition

2. Control unit

3. Tension rod

4. $90^{\circ}$ arch

5. Load introduction frame

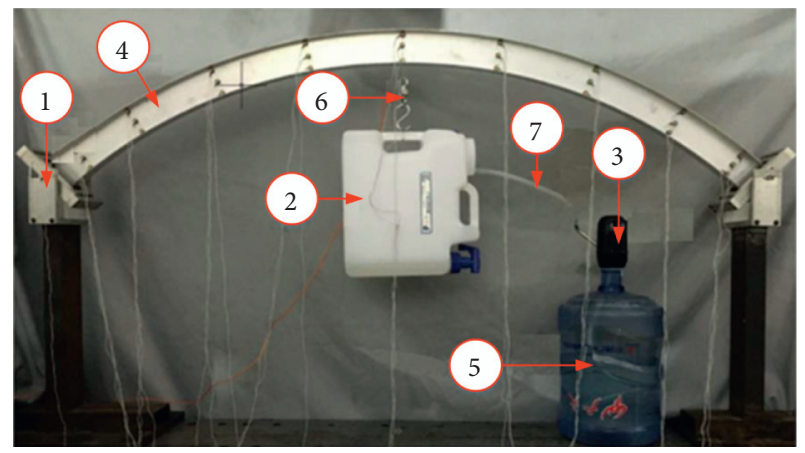

Load device
1. Support
2. Loading tank
3. Automatic water pump
4. I-section aluminum arch

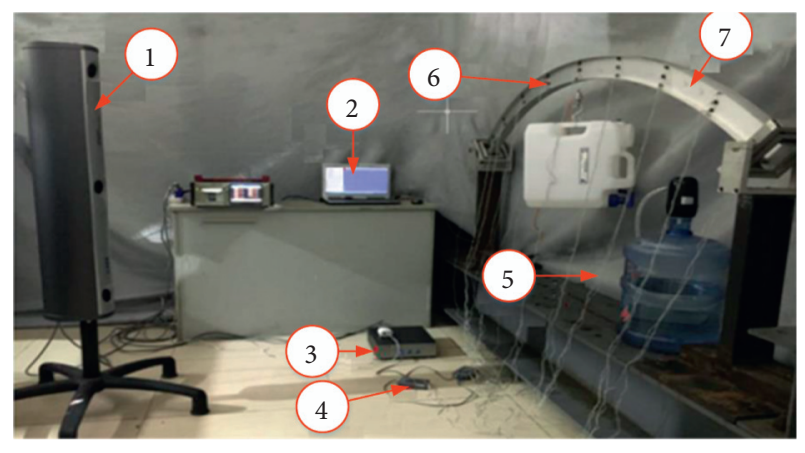

Test layout and NDI real - time displacement measurement

1. Positioning sensor

5. Strober extension cable

2. Computer

3. System control unit

4. Market strober

FIGURE 2: Setup for the lateral-torsional buckling test [37]. properties, cross-sectional properties, and geometric properties ([55]:17). These parameters are associated with the imperfections of a member. Imperfections that influence the LTB resistance include the material nonlinearity, initial geometric imperfections, and residual stresses [1].

The following is a brief discussion of the several factors and parameters in the design of LTB of freestanding circular thin-walled arches. The focus of this study is on pinned and fixed arches subjected to CCL. In addition, several studies have been reported in other literature for arches subjected to uniform compression and bending [37].

3.1. Elastic Lateral-Torsional Buckling. Studies reported on arches subjected to CCL are rare. This is because this load type may cause combined bending and axial compressive actions that are nonuniform with complicated distribution patterns in the arch $[28,58]$. Also, the combined action develops a more complex prebuckling stress state compared to arches in uniform compression or uniform bending [33]. For arches with fixed ends, the analysis is more complex due to the additional bending moment developed at the supports. The interaction between the axial compressive and bending actions in an arch is related to many factors that influence the LTB. Some of these factors include the in-plane slenderness $\left(S / r_{x}\right)$, where $S$ is the arc length and $r_{x}$ is the radius of gyration, modified out-of-plane slenderness $\left(\lambda_{\mathrm{am}}\right)$, included angle $(2 \Theta)$, imperfections (i.e., material and geometric nonlinearities and residual stresses), loading, and boundary conditions [59]. The combined actions in pinned and fixed freestanding circular arches subjected to point load $F$ and fail by LTB are shown in Figure 3 .

From Figure 3, $H$ and $V$ are the horizontal and vertical reactions, $M_{d}$ is the end moment reaction, $L$ is the span arch length, $w, v$, and $u$ are the tangential, radial, and lateral displacements of the centroid of the cross section, respectively, $\phi$ is the twist rotation of the cross section, $2 \Theta$ is the included angle, $\theta$ is angular position of the bending moment, $\mathrm{cg}$ and sg are the center of gravity and shear center, respectively, $F_{T}, F_{S}$, and $F_{B}$ represent the applied point load at different heights, that is, top flange, shear center, and bottom flange, respectively, and $x$ and $y$ are the coordinates of a point load in the principle axis of the cross section.

Papangelis and Trahair [60] used an in-house finite element analysis method to study the elastic flexural-torsional buckling (FTB) of double symmetric arches. The studied arches were pin-supported and subjected to different load types including point loads. The authors concluded that the height of the point load from the arch centerline influenced the buckling load and thereby provided an expression to account for the effect. From the effect, they observed that as the point load distance increased below the centerline, the buckling load increased and approached the second mode buckling load. Later, Papangelis and Trahair [34] proposed a finite element method for analyzing elastic FTB of circular arches from monosymmetric $\mathrm{Al}$ I-sections subjected to CCL with simple, pinned, and fixed supports. The proposed numerical solution was validated with the first of its kind 


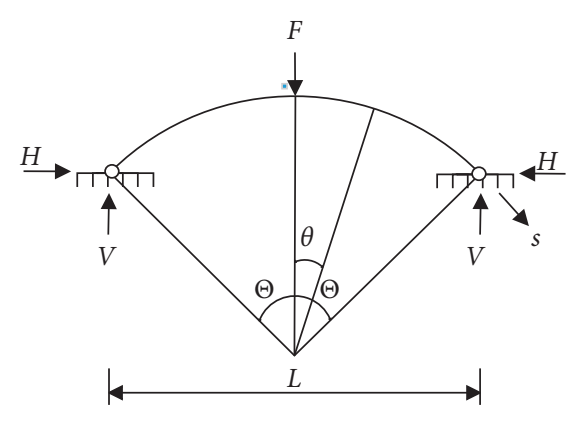

(a)

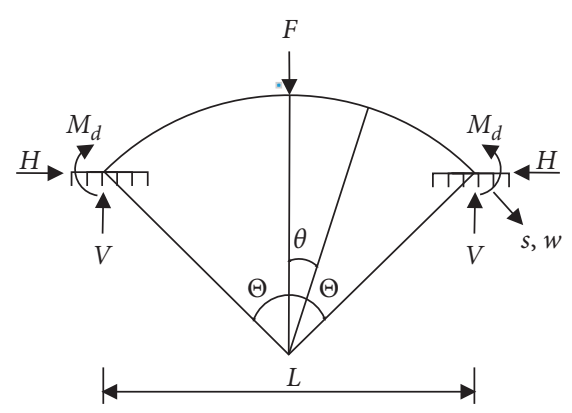

(b)

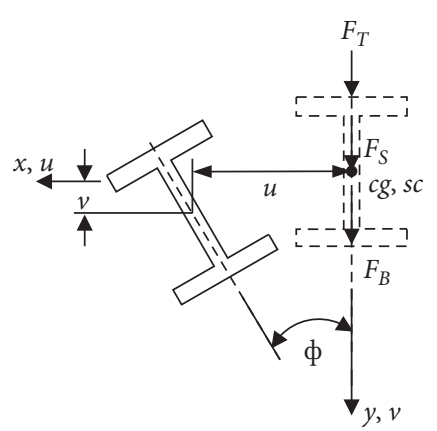

(c)

Figure 3: Reactions on pinned and fixed arches subjected to central concentrated load (redrawn from [58]). (a) Pinned arch. (b) Fixed arch. (c) Lateral-torsional buckling.

experimental solution for simply supported arches reported by Papangelis and Trahair [43]. The critical loads for both methods showed good agreement with a 0.98 mean value and 0.08 standard deviation. Nevertheless, the former and latter studies assumed the prebuckling stress state as trivial. However, Pi et al.'s [3] study stated that such an assumption may invalidate the solution accuracy due to the presence of combined compressive and bending actions that resulted from the applied point loads.

$\mathrm{Pi}$ and Trahair [39] proposed a 3D nonlinear finite element model that included the Wagner (warping) and postbuckling effects for analyzing elastic arches of double symmetric sections with fixed, pinned, and simply supported end conditions. Their proposed solution showed good agreement with existing solutions as shown in Table 1, investigating the effects of the included angles with respect to the load position on the buckling load. These authors observed that, for pinned arches with applied load at the crown and included angles of $0^{\circ}<2 \Theta \leq 60^{\circ}$, the FTB resistance significantly reduced due to the existence of large developed axial compression actions. Similar behavior was observed for arches having fixed supports with the buckling load magnitude being $50 \%$ greater than that of pinned end arches. On the other hand, at a large angle of about $120^{\circ}$, the negative moments at the supports for fixed arches are more important and significantly increase the FTB resistance to about $175 \%$ compared to pinned end arches.

In this regard, Pi et al.'s [3] study used the principle of stationary potential energy to derive the first analytical solutions for the elastic LTB load of circular pinned arches with in-plane fixed and out-of-plane pinned supports. The arches were of double symmetric cross sections subjected to CCL. Their developed solution shown in equation (1) demonstrated good agreement with results from FEA software ANSYS and other in-house developed FE codes as shown in Figure 4. The authors also observed that the boundary conditions, slenderness, cross section, and load height significantly affect the LTB load of arches as shown in Figure 4. Some of these effects have been revealed by the studies of Pi and Trahair [39] and Papangelis and Trahair [60]:
TABLE 1: Comparison of results for arches [39, 61].

\begin{tabular}{lcccc}
\hline \multicolumn{4}{c}{ Buckling load or moment } \\
$\begin{array}{l}\text { Included } \\
\text { angles in } \\
\text { degrees }\end{array}$ & $\begin{array}{c}\text { Solutions } \\
\text { by Pi and } \\
\text { Trahair [39] } \\
\text { in kN }\end{array}$ & $\begin{array}{c}\text { Analytical } \\
\text { solutions in } \\
\mathrm{kN}\end{array}$ & $\begin{array}{c}\text { Solutions } \\
\text { by Pi and } \\
\text { Trahair [39] } \\
\text { in kNm }\end{array}$ & $\begin{array}{c}\text { Solutions } \\
\text { by Yang } \\
\text { et al. [61] in } \\
\mathrm{kNm}\end{array}$ \\
\hline 30 & 3.6232 & 3.6502 & 91.54 & 91.25 \\
60 & 2.7496 & 2.7633 & 44.76 & 44.54 \\
90 & 1.6959 & 1.6999 & 26.13 & 26.07 \\
120 & 0.7836 & 0.7836 & 14.52 & 14.47 \\
150 & 0.1962 & 0.1966 & 6.37 & 6.30 \\
\hline
\end{tabular}

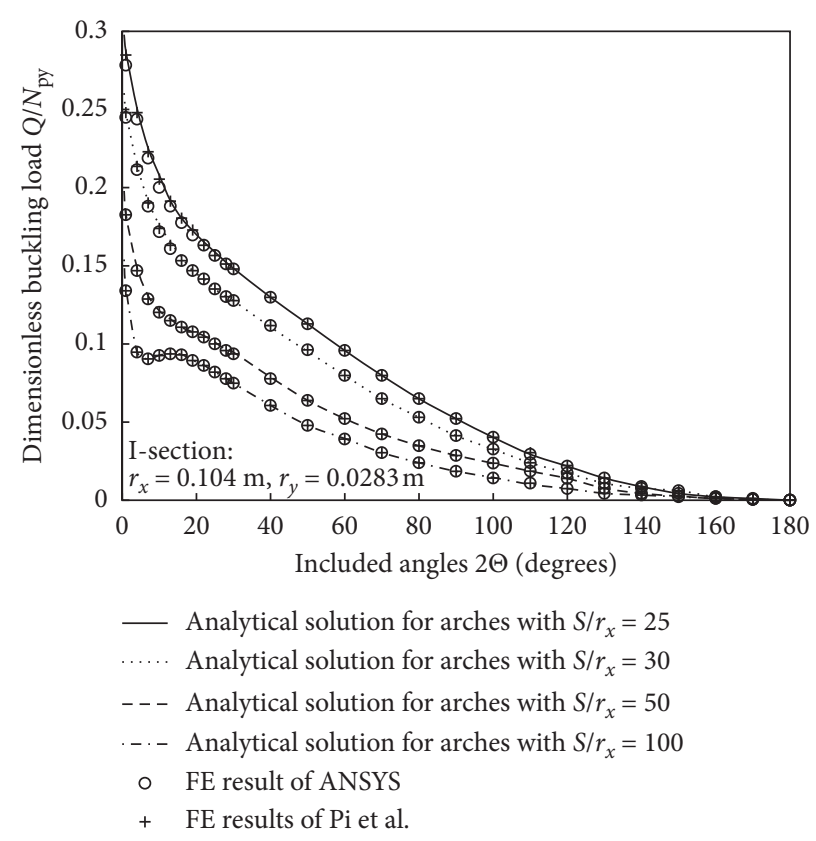

FIgURE 4: Comparison of lateral-torsional buckling results for Isection arches from different methods [3]. 


$$
\begin{aligned}
A_{1}\left(\frac{Q_{\mathrm{cr}}}{N_{y}}\right)^{2}+B_{1} \frac{Q_{\mathrm{cr}}}{N_{y}}+\left(1-a_{n}^{2}\right) & =0, \quad \text { where } \mathrm{A}_{1}, \mathrm{~B}_{1}, \text { and } \mathrm{C}_{1} \text { as defined as, } \\
A_{1} & =-\left(\eta_{1} \eta_{3}-\eta_{2}^{2}\right), \\
B_{1} & =\frac{\left(\eta_{3} b^{2}-\eta_{1} b^{2}-\eta_{1} a^{2}+\eta_{3} a^{2} b^{4}-2 a b^{3} \eta_{2}-2 a b \eta_{2}\right)}{b^{2}}, \\
C_{1} & =\left(1-a^{2}\right)^{2}, \\
a & =\frac{(S)}{\pi R}, a n d b=\frac{\pi M_{\mathrm{ys}}}{N_{y} S}, \\
N_{y} & =\frac{\pi^{2} E I_{y}}{S^{2}}, \\
N_{s} & =\frac{1}{r_{0}^{2}}+\left(G J+\frac{\pi^{2} E I_{w}}{S^{2}}\right), \\
M_{y s} & =\sqrt{r_{0}^{2} N_{y} N_{s}},
\end{aligned}
$$

where $M_{\mathrm{ys}}$ is the first mode elastic FTB moment of the corresponding simply supported beam with same length $S$ under uniform bending, $P_{y}$ is the first mode elastic flexural buckling load about the minor principal axis of the cross section, $P_{\text {sn }}$ is the first mode elastic flexural buckling load about the column axis of the corresponding pinned column with the same length $S$ (length of the arch) under uniform compression, $r_{O}$ is the polar radius of gyration of the cross section, $E$ is Young's modulus of elasticity, $G$ is the shear modulus of elasticity, $J$ is the torsion section constant, $I_{w}$ is the moment of inertia of the web, $I_{x}$, and $I_{y}$ are the second moments of the area about the $x$-axis and $y$-axis (major and minor axis moment of inertia), $A$ is the area of cross section, $Q_{\mathrm{cr}}$ is the LTB load, and $\eta_{1}, \eta_{2}$, and $\eta_{3}$ are parameters that account for the effects of varying axial compressive force and bending moment.

Nevertheless, the authors concluded that the load height above the shear center reduces the LTB load, whereas, below the shear center, it increases the LTB load. Also, the in-plane fixed conditions increase the LTB load as compared to outof-plane pinned ends with greater significance for shallow arches. Likewise, increase in slenderness reduces the LTB load with significant effects depending on the cross section and included angle.

In this regard, $\mathrm{Pi}$ and Bradford [28] used a cross section that is identical to Pi et al.'s [3] and derived an analytical solution for the elastic LTB load for thin-walled, pinned ends circular arches having in-plane rotational end restraints subjected to CCL. The authors' proposed solution showed very small difference to independent curved-beam element model of Pi et al. [62] and FE results of ANSYS. Although the study did not focus on the effects of slender ratios or the included angles, both were noticed to influence the LTB load, with no attribution to the exact quantification of their effects. However, the effects were similar to those reported by
Pi et al. [3]. Likewise, the in-plane rotational end restraint was noticed to profoundly influence the LTB load of arches.

Liu et al.'s [36] study used the same cross section as Pi et al.'s [3] and investigated the elastic out-of-plane LTB of fixed circular arches subjected to CCL. The authors carried out an accurate prebuckling analysis on the combined axial compressive and bending actions. Through the theory of stationary potential energy in conjunction with RayleighRitz methods, the authors proposed an LTB load solution shown in the following equation:

$$
\left(\mathrm{K}_{e}-\mathrm{Q}_{\mathrm{cr}} \mathrm{K}_{g}\right) g=0,
$$

where $Q_{\mathrm{cr}}$ is the LTB load, $\mathrm{K}_{e}$ is the lateral-torsional stiffness matrix related to the strain energy, $K_{g}$ is the lateral-torsional stability matrix, and $g$ is the vector quantity representing the lateral displacement and twist. The analytical solutions using steel properties showed good agreement with FEA obtained results using ANSYS software with less than 1\% deviation. Also, the authors noticed the slender ratios, load height, and end supports to influence the LTB load and represented the effects on the LTB load magnitude in graphical form as shown in Figure 5 for an I-section. $y_{q}$ is the central line distance and the positive $y_{q}$ values represent the distance above centerline. The effects as shown in Figure 5 are like those reported in the abovementioned studies and vary with uniformly across the included angles.

Similarly, Liu et al. [33] studied steel arches with pinned supports having in-plane rotationally restrained ends, subjected to arbitrary radial concentrated load. Lu et al. [37] extended the study of Liu et al. [33] by accounting for thermal expansion and shear deformation. In a similar study, Lu et al. [37] extended the study of Lu et al. [63] by investigating through experimental studies the elastic outof-plane buckling of circular arches. The arches were of double symmetric Al I-sections subjected to central radial 


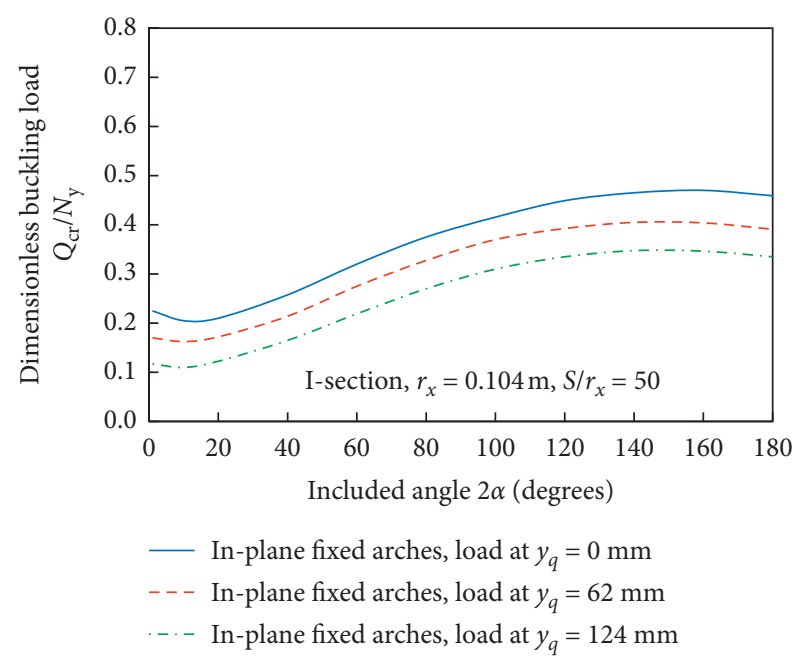

(a)

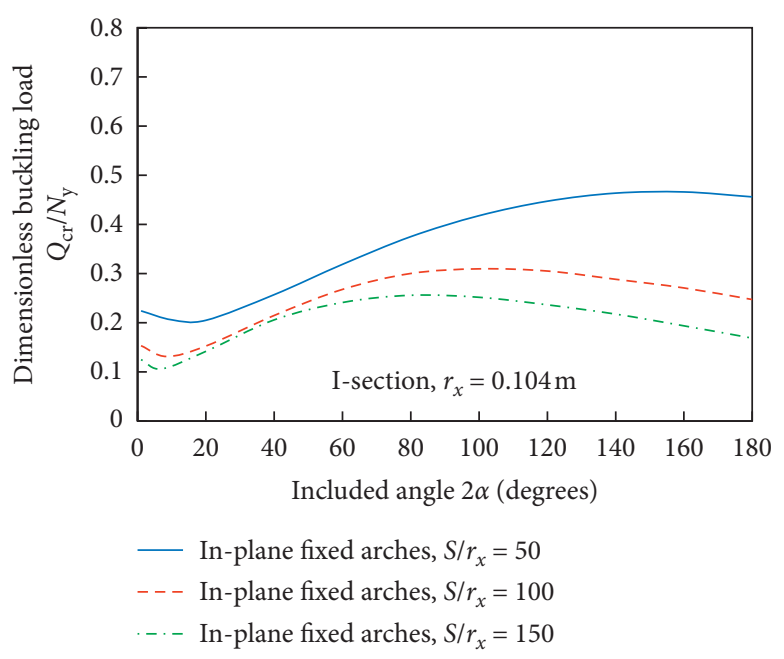

(b)

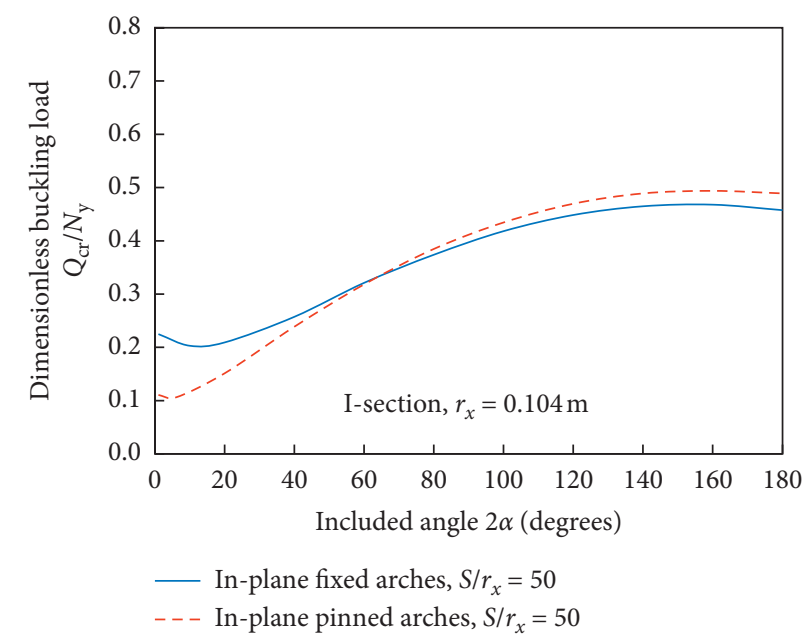

(c)

FIGURE 5: Lateral-torsional buckling loads effects of (a) load height, (b) slenderness, and (c) in-plane boundary conditions [36].

point load with pinned supports. The theoretical and experimental results showed good agreement with less than 5\% deviation. The influences of the load height, end supports, slender ratio, and included angles were like those reported in the mentioned studies. However, Lu et al. [37] reported a small difference in the LTB load between arches of in-plane pinned and in-plane fixed ends for both experimental and theoretical results.

In summary, the above studies related to the LTB of fixed and pinned arches subjected to CCL had focused more on double symmetric sections. No studies were reported on the LTB of fixed or pinned arches of channel sections subjected to CCL. Also, all the reported studies focused on elastic analysis. As a result, the studies ignored the imperfections' effects on the LTB load but only dealt with those of load height, slender ratios, included angles, and end supports. Due to the nature of these effects, as they vary in magnitude at different included angles, the quantification of their effects on the LTB loads was represented graphically with some examples illustrated in Figures 4-6.

$$
\frac{N^{*}}{\phi \alpha_{\mathrm{any}} N_{\mathrm{acys}}}+\frac{M^{*}}{\phi \alpha_{\mathrm{amy}} M_{\mathrm{amys}}} \leq 1,
$$

3.2. Inelastic Lateral-Torsional Buckling. A study by $\mathrm{Pi}$ and Trahair [59] used a nonlinear inelastic finite element method to develop a general method to design against inelastic lateral bucking. The authors used arches of double symmetric steel I-section with pinned ends subjected to general vertical loading inclusive of CCL. The obtained theoretical results showed little deviation from results obtained from the computer program PRESA. Based on their findings, the authors concluded that the included angle and load distribution significantly affect the lateral buckling strength of steel arches, while the initial crookedness, twist, and residual stresses are important on the strengths of arches. The included angle and load gave similar effects to those of elastic analysis, while the residual stresses reduce the strength to about $11 \%$ for an arch with modified slenderness. Likewise, 
the initial crookedness may reduce the strength up to $30 \%$ based on the imperfection value and loading. Nevertheless, the study had no experimental data to validate the inelastic finite element method.

Another study by Pi and Bradford [58] developed a rational 3D nonlinear finite curved beam-element model to investigate the elastic and elastic-plastic FTB and postbuckling of double symmetric steel and Al I-sections arches subjected to CCL with fixed and pinned supports. Pi and Bradford [41] used the same FE model and proposed design equations against out-of-plane failure for fixed steel I-section circular arches that considered the effects of initial out-of-plane crookedness and residual stress. The arches were subjected to different loading inclusive of in-plane transverse load. The former study compared the results with test results reported by Papangelis and Trahair, [64] which showed very little deviation as revealed in Figure 6. Meanwhile, the latter study assumed the accuracy of the FE model as verified by $\mathrm{Pi}$ and Trahair [59]. Both studies revealed that the included angle, slenderness, and end supports influence the LTB load with elastic buckling load for pinned arches being smaller as compared to fixed arches. Although the studies ignored the effects of material nonlinearity from the curved process, they found the initial imperfections and residual stresses to be important for the strength of the arches. That is, an increase in initial imperfection or residual stress reduces the LTB load; thus, the elastic LTB load is lower than the inelastic LTB load. Pi and Bradford (2005) provided a general stability design check which took similar format to that proposed by $\mathrm{Pi}$ and Trahair [59] as given in equation (3) with an addition coefficient $\phi$ (whereby $\phi$ is the capacity reduction factor for uniform compression and bending): where $N_{\text {acys }}$ and $M_{\text {amys }}$ are the out-of-plane strength for fixed steel arch in uniform compression and uniform bending, respectively, $\alpha_{\text {ny }}$ and $\alpha_{\text {amy }}$ are the axial compression and moment modification factors, and $N^{*}$ and $M^{*}$ are the nominal maximum axial compression and maximum moment calculated by firstorder in-plane elastic analyses for the arch.

For better understanding of the buckling behavior of arches, La Poutré et al. [57] conducted several experimental studies. Spoorenberg et al. [65] studied the out-of-plane stability of roller bent freestanding circular arches of steel double symmetric I-sections subjected to single load at the crown using experimental tests and FEA software package ANSYS. The difference in the results was within a 1.18 ratio, and the difference among repeated test results is less than $3.2 \%$. Based on the FEA results, the authors concluded that the imperfections affected by the roll bending process due to plastic deformation to form an arch affect the carrying load capacity of the arch. However, the contrary was observed from the experimental test that shown insignificant effect. Similar observation was made for included angle, whereby an increase in the included angle resulted in slight increase in the failure load.

Guo et al. [46] studied the out-of-plane inelastic buckling strength of fixed steel arches using experimental test and commercial software ANSYS. Both methods yielded results with small deviation. Based on the obtained results, the authors concluded that the out-of-plane inelastic buckling strength of these arches is also influenced by the initial outof-plane geometric imperfections, in-plane loading pattern, and out-of-plane elastic buckling modes. The obtained results were used to develop lower bound interaction equations for predicting out-of-plane inelastic buckling strength in the design of fixed circular arches against out-of-plane failure. The developed equation (4) took a similar form to equation (3) in which when the moment application factor $\delta_{\text {by }}>1.4$, a $2^{\text {nd }}$ order in-plane elastic analysis should be carried out to obtain $N^{*}$ and $M^{*}$. A 0.9 safety factor $\varphi$ was recommended for the proposed design:

$$
\frac{N^{*}}{\alpha_{\text {any }} N_{\text {anys }}}+\frac{\delta_{\text {by }} M^{*}}{\alpha_{\text {amy }} M_{\text {amys }}} \leq \varphi .
$$

Likewise, Dou et al. [45] investigated using experimental test the flexural-torsional ultimate resistance of pinned circular arches made of double symmetric I-sections subjected to concentrated loads at different points. The authors observed small disparity between the test results and those obtained from software package ANSYS using BEAM188. Both methods indicated that the geometric imperfections and loading conditions affect the ultimate buckling modes and loads. Also, the authors concluded that pinned arches buckle in an asymmetric double-wave S-shaped buckling mode. This is different from the one-wave C-shaped buckling mode for fixed arches [46].

From the above reviewed literature, no theoretical solutions have been reported for inelastic out-of-plane LTB of fixed arches. Also, among the reported results, no equation was proposed to compensate for the effects of initial imperfections and residual stresses on the LTB load as that proposed by Papangelis and Trahair [60] to account for point of load height. However, one can conclude that the insufficiency is because of the complex nature involved in the analytical method. Also, no information has been reported for the out-of-plane LTB of Al channel arches with fixed supports subjected to CCL, addressing the effects of included angle, slender ratio, initial geometric imperfections, material nonlinearity, and residual stresses, be it through experimental, numerical, or analytical methods.

3.3. Summary and Discussion. Numerous research studies have been reported on the out-of-plane LTB of freestanding circular arches. Most of these studies paid attention to double symmetric I-sections as compared to monosymmetric sections like channels, although such sections may behave differently under LTB due to their shear center position. The shear center position makes such sections experience eccentric loading in structures. This factor among others mentioned in Sections 3.1 and 3.2 has been well studied by researchers using one or many of the measure buckling methods mentioned in Section 2. The numerical methods can be cited as the most preferred for buckling analysis. This is because numerical methods are less complex for inelastic analysis as compared to the analytical ones. Also, numerical methods are less expensive as compared to 


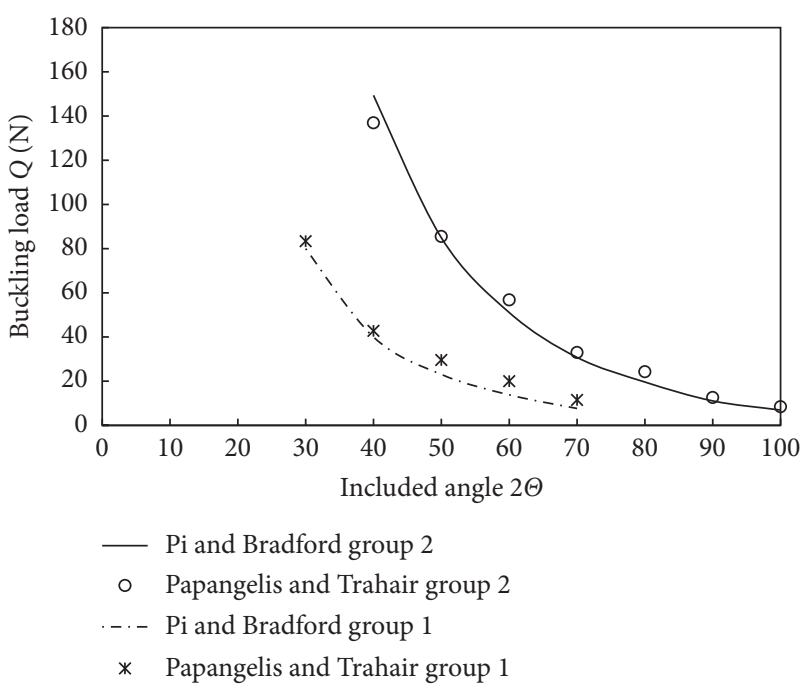

FIGURE 6: Comparison of numerical and test results [58, 64].

the experimental methods that involve specimens, equipment, and labor cost. However, numerical methods may provide results close to experimental results depending on the input variables and limitations mentioned in Section 2.2.

Arches subjected to CCL experience bending and compression actions. The interactions between both actions in arches are related to the several factors that influence the LTB load and behavior of arches. These factors include end supports, load height, included angle, slenderness ratios, and imperfections. How these factors increase or decrease the axial compressive force and bending moment may determine the significant factor on the LTB behavior, resistance, stability, and strength of the arch. Although these factors influence the LTB separately, they in turn affect one another.

Fixed and pinned supports significantly influence the axial compression and bending actions in arches subjected to CCL and consequently affect the LTB resistance. From this review, for I-sections arches with included angles $0^{\circ}<2 \Theta<60^{\circ}$ at $S / r_{x} \geq 50$, the fixed arches have high LTB load compared to pin-ended arches. A maximum reduction of up to $50 \%$ was observed between LTB load magnitudes, which varies with included angles, as their axial compressive force and bending moment across the arc length also vary. These differences in magnitudes were observed from the review to depend on the axial compression and bending actions. The high magnitudes of the fixed arches LTB loads at $2 \Theta<60^{\circ}$ are due to the low axial compressive force and bending moment developed in the pinned arches as compared to the fixed arches with $67 \%$ difference between both peak values. Also, at $S / r_{x}>50$, the included angles at which LTB load for fixed arches is greater than pinned arches decrease towards $0^{\circ}$ and vice versa. This implies that, for slenderer arches, the LTB for fixed arches occurs at lower included angles as compared to its counterpart arches with pinned ends. It was also observed that this behavior in magnitude depends on the axial compression and bending action. That is, the included angles at which the axial compression and bending actions are lower corresponds to the included angles at which the LTB load for the arches is higher. Similar observations were made for double symmetric rectangular sections. However, the magnitudes of the LTB loads and included angles at which their peak values occurred were different, thus making it too comprehensive to quantify the exact effect on the end support to the LTB for arches and thereby indicating the need to further study the different cross sections and their behavior with respect to their supports.

The slenderness also has a major influence on the axial compression and bending action on an arch and thus impacts the LTB load of arches. An increase in slender ratio, be it fixed or pin-ended supports, decreases the LTB load. For double symmetric sections with radius of gyration $r_{x}=0.104 \mathrm{~m}$, a LTB load reduction of up to $45 \%$ was noted between slender ratios of 100 and 50 for fixed ends arches and there was a $35 \%$ reduction for pin-ended arches with $67 \%$ difference between their peak axial compressive force and bending moment values. Also, this indicated that the peak axial compressive force and bending moments percentage difference between the two slender ratios for fixed and pinned ends arches remains the same. For instance, at $S /$ $r_{x}=25$ and 100, the axial compressive force and bending moment for the different supports yielded $119 \%$ difference in their peak values. Nevertheless, the decrease in axial compressive force and bending moment based on the decreased slender ratio difference decreases the percentage reduction between the LTB loads.

Irrespective of the end supports and slender ratios, the load height also influences the LTB load of arches. For double symmetric I-section at $S / r_{x}=50$, the positioning of the load at crown above the centerline was found to reduce the LTB load by $26 \%$. Based on the observations made in the review, this should increase as the web width increases. On the contrary, the LTB load was found to reduce by $9 \%$ for double symmetric rectangular sections due to their high torsional stiffness, that is, high resistance to LTB based on the high $I_{y} / I_{x}$ ratio, where $I_{y}$ is the minor moment of inertia and $I_{x}$ is the major moment of inertia. On the other hand, at $S / r_{x}=25$, the LTB load was found to increase by $14 \%$ from the centerline with the load acting bottom of the flange. Although the reduction and increase of the LTB load vary across the included angles, the cross section effects also influence the magnitude to which the load height affects the LTB. However, such information for channel sections is insufficient.

The included angles of arches, whether shallow or deep, have significant impact on the LTB load of arches. These differences differ in magnitude and behavior with respect to the cross section and are associated with the other mentioned factors. As such, from the review, it was found that the plots of load height, slender ratios, and end supports effects varied across the included angles. This variation was observed to be influenced by the axial compression and bending actions at the different included angles whose magnitudes at given included angles are based on their distribution across the arc length at that specific angle. As such, the magnitude at which the included angles impact the LTB load behavior depends on the supports, load height, slenderness, cross section, and imperfection factors. 
Imperfections are also crucial factors that influence the LTB of arches subjected to CCL. These referred imperfections include material nonlinearity, initial geometric imperfection, and residual stresses. The imperfections affect the LTB resistance asymptotically. This is because each of these parameters is associated with the stiffness of the members that determine the buckling load. The initial geometric imperfection decreases the strength of the arch as it increases. This is because, in most cases, it puts the arch geometry in an undesirable position by shifting the shear center causing eccentric loading. The magnitude to which this influences the LTB load depends on the severity of that initial geometric imperfection. Also, the roll bending process may also enhance the existing residual stresses due to the plastic deformations during bending to form the arch. When taken into consideration, based on the stress pattern distribution across the member, the flange edge may yield much earlier than expected. This effect in steel profiles has been shown to affect the arch strength by up to $11 \%$. In addition, the roll bending process may reduce the yield and ultimate strength of the arch when deformed to form the arch. This reduces the material carrying capacity and thus influences the LTB.

From the reviewed literature, it is evident that no study has reported on the LTB of fixed arches of Al channels subjected to CCL. This implies that no proposed closed-form solutions exist for these arches. Also, no FEA or experimental studies have reported on the LTB behavior of such arches. However, there exist proposed elastic closed-form solutions for fixed arches of double symmetric I-section subjected to CCL. From the above discussion on the several factors that influence LTB, one cannot conclude that the same LTB behavior for fixed arches of the $\mathrm{Al}$ channel section subjected to CCL will suffice. Also, it is clear from the reviewed literature that direct application of symmetric section solutions may yield inaccurate solutions for channel sections.

Therefore, since LTB is influenced by the several factors mentioned in the reviewed literature and considering the fact that these factors' magnitudes differ from a cross section to another, there is a need for further research on the effect these factors may have on different cross sections that are not reported. Also, it is imperative to carry out further analytical studies on the imperfection effects on the LTB of fixed end arches subjected to CCL.

\section{Conclusion}

Lateral-torsional buckling is found to be influenced by loading, boundary conditions, included angles, slenderness, cross section, and imperfections. However, no information or solution has been reported for fixed ends arches of aluminum alloy channel sections subjected to central concentrated load. Due to the shear center position that has resulted in the eccentric loading of most channel sections in practice, the direct use of information reported for double symmetric steel and aluminum I-sections may lead to inaccurate solutions and predictions. However, the reported information on these double symmetric sections can be modified and used for monosymmetric sections. This, therefore, justifies the need to adopt similar procedures to further study the lateral-torsional buckling of fixed end arches of channel sections subjected to central concentrated load.

\section{Abbreviations}

LTB: Lateral-torsional buckling

FTB: Flexural-torsional buckling

FEA: Finite element analysis

Al: Aluminum

3D: Three-dimensions

CCL: Central concentrated load

FEM: Finite element model.

\section{Conflicts of Interest}

The authors declare that they have no conflicts of interest.

\section{Authors' Contributions}

All authors jointly contributed to the development of this journal article.

\section{Acknowledgments}

This research work was supported by the Vaal University of Technology. The authors want to acknowledge the Department of Mechanical Engineering at the Vaal University of Technology for facilitating this work. This research was funded by the NRF Block grant under the guidance of the Vaal University of Technology.

\section{References}

[1] R. C. Spoorenberg, Structural Properties and Out-of-Plane Stability of Roller Bent Steel Arches, Technische Universiteit Eindhoven, Eindhoven, Netherlands, 2011.

[2] D. B. La Poutré, Inelastic Spatial Stability of Circular Wide Flange Steel Arches, Technische Universiteit Eindhoven, Eindhoven, Netherlands, 2005.

[3] Y.-L. Pi, M. A. Bradford, and G.-S. Tong, "Elastic lateraltorsional buckling of circular arches subjected to a central concentrated load," International Journal of Mechanical Sciences, vol. 52, no. 6, pp. 847-862, 2010.

[4] R. D. Ziemian, Guide to Stability Design Criteria for Metal, R. D. Ziemian, Ed., , John Wiley \& Sons, Inc., Hoboken, NJ, USA, Sixth edition, 2010.

[5] L. Dahmani and S. Drizi, "Lateral torsional buckling of an eccentrically loaded channel section beam," Strength of Materials, vol. 47, no. 6, pp. 912-916, 2015.

[6] M.-Y. Kim, B.-C. Min, and M.-W. Suh, "Spatial stability of nonsymmetric thin-walled curved beams. I: analytical approach," Journal of Engineering Mechanics, vol. 126, no. 5, pp. 497-505, 2000a.

[7] M. Brettle, "Lateral torsional buckling and slenderness," NCS, vol. 14, no. 9, pp. 30-34, 2006.

[8] K. Mudenda and A. Zingoni, "Lateral-torsional buckling behavior of hot-rolled steel beams with flange upstands," Journal of Constructional Steel Research, vol. 144, pp. 53-64, 2018. 
[9] H. Ozbasaran, R. Aydin, and M. Dogan, "An alternative design procedure for lateral-torsional buckling of cantilever I-beams," Thin-Walled Structures, vol. 90, pp. 235-242, 2015.

[10] M. Bajer, J. Barnat, and J. Pijak, "Lateral torsional buckling of selected cross-section Types," Procedia Engineering, vol. 190, pp. 106-110, 2017.

[11] S. P. Timoshenko and J. M. Gere, Theory of Elastic Stability, McGraw Hill, New York, NY, USA, 2nd edition, 1961.

[12] V. Z. Vlasov, Thin-walled Elastic Beams, National Technical Information Service, Springfield, VA, USA, 1961.

[13] Y.-L. Pi and N. S. Trahair, "Out-of-plane inelastic buckling and strength of steel arches," Journal of Structural Engineering, vol. 124, no. 2, pp. 174-183, 1998.

[14] C. H. Yoo and P. A. Pfeiffer, "Elastic stability of curved members," Journal of Structural Engineering, vol. 109, no. 12, pp. 2922-2940, 1983.

[15] S. Rajasekaran and E. Ramm, "Discussion of "flexural-torsional stability of curved beams" by Chai Hong Yoo (december, 1982)," Journal of Engineering Mechanics, vol. 110, no. 1, pp. 144-148, 1984.

[16] J. P. Papangelis and N. S. Trahair, "Flexural-torsional buckling of arches," Journal of Structural Engineering, vol. 113, no. 4, pp. 889-906, 1986.

[17] Y. B. Yang and S. R. Kuo, "Static stability of curved thinwalled beams," Journal of Engineering Mechanics, vol. 112, no. 8, pp. 821-841, 1986.

[18] Y. B. Yang and S. R. Kuo, "Effect of curvature on stability of curved beams," Journal of Structural Engineering, vol. 113, no. 6, pp. 1185-1202, 1987.

[19] S. Rajasekaran and S. Padmanabhan, "Equations of curved beams," Journal of Engineering Mechanics, vol. 115, no. 5, pp. 1094-1111, 1989.

[20] Y. B. Yang, S. R. Kuo, and J. D. Yau, "Use of straight-beam approach to study buckling of curved beams," Journal of Structural Engineering, vol. 117, no. 7, pp. 1963-1978, 1991.

[21] N. S. Trahair, Flexural-Torsional Buckling of Structures New Directions in Civil Engineering, Chapman \& Hall, London, UK, 1993.

[22] Y. J. Kang and C. H. Yoo, "Thin-walled curved beams. I: formulation of nonlinear equations," Journal of Engineering Mechanics, vol. 120, no. 10, pp. 2072-2101, 1994.

[23] M. A. Bradford, N. S. Trahair, and Y. Y. Chen, "A further study of flexural-torsional buckling of elastic arches," International Journal of Structural Stability and Dynamics, vol. 5, no. 2, pp. 163-183, 2005.

[24] Y.-L. Pi, M. A. Bradford, and F. Tin-Loi, "Flexural-torsional buckling of shallow arches with open thin-walled section under uniform radial loads," Thin-Walled Structures, vol. 45, no. 3, pp. 352-362, 2007.

[25] M. A. Bradford and Y.-L. Pi, "Elastic flexural-torsional instability of structural arches under hydrostatic pressure," International Journal of Mechanical Sciences, vol. 50, no. 2, pp. 143-151, 2008.

[26] M. A. Bradford and Y.-L. Pi, "A new analytical solution for lateral-torsional buckling of arches under axial uniform compression," Engineering Structures, vol. 41, no. 4, pp. 14-23, 2012.

[27] Y. H. Yang, C. X. Chen, and M. J. Fang, "Lateral-torsional buckling Strength and design of Steel arches," Advanced Materials Research, vol. 250-253, no. 5, pp. 2645-2649, 2011.

[28] Y.-L. Pi and M. A. Bradford, "Lateral-torsional buckling analysis of arches having in-plane rotational end restraints under uniform radial loading," Journal of Engineering $\mathrm{Me}$ chanics, vol. 139, no. 11, pp. 1602-1609, 2013.
[29] Y.-L. Pi and M. A. Bradford, "Effects of prebuckling deformations on the elastic flexural-torsional buckling of laterally fixed arches," International Journal of Mechanical Sciences, vol. 46, no. 2, pp. 321-342, 2004.

[30] Y.-L. Pi and M. A. Bradford, "Elastic flexural-torsional buckling of fixed arches," The Quarterly Journal of Mechanics and Applied Mathematics, vol. 57, no. 4, pp. 551-569, 2004.

[31] M. A. Bradford and Y.-L. Pi, "Flexural-torsional buckling of fixed steel arches under uniform bending," Journal of Constructional Steel Research, vol. 62, no. 1-2, pp. 20-26, 2006.

[32] C. Dou, Y.-L. Guo, Y.-L. Pi, S.-Y. Zhao, and M. A. Bradford, "Effects of shape functions on flexural-torsional buckling of fixed circular arches," Engineering Structures, vol. 59, pp. 238-247, 2014.

[33] A. Liu, H. Lu, J. Fu, and Y.-L. Pi, "Lateral-torsional buckling of fixed circular arches having a thin-walled section under a central concentrated load," Thin-Walled Structures, vol. 118, pp. 46-55, 2017.

[34] J. P. Papangelis and N. S. Trahair, "Buckling of monosymmetric arches under point loads," Engineering Structures, vol. 10, no. 4, pp. 257-264, 1988.

[35] Y.-L. Pi and M. A. Bradford, "Lateral-torsional elastic buckling of rotationally restrained arches with a thin-walled section under a central concentrated load," Thin-Walled Structures, vol. 73, pp. 18-26, 2013.

[36] A. Liu, H. Lu, J. Fu, and Y.-L. Pi, "Lateral-Torsional buckling of circular Steel arches under arbitrary radial concentrated load," Journal of Structural Engineering, vol. 143, no. 9, 2017.

[37] H. Lu, A. Liu, M. A. Bradford, and Y. L. Pi, "Experimental investigation of out-of-plane buckling of circular arches under a central radial point load," Thin-Walled Structures, vol. 148, 2019.

[38] C. H. M. De Louw, Design rule for lateral torsional buckling of channel sections, Eindhoven University of Technology, Eindhoven, Netherland, 2007.

[39] Y.-L. Pi and N. S. Trahair, "Three-dimensional nonlinear analysis of elastic arches," Engineering Structures, vol. 18, no. 1, pp. 49-63, 1996.

[40] K. Kang and C. W. Bert, "Flexural- torsional buckling analysis of arches with warping using DQM," Engineering Structures, vol. 19, no. 3, pp. 247-254, 1997.

[41] Y.-L. Pi and M. A. Bradford, "Out-of-plane strength design of fixed steel I-section arches," Journal of Structural Engineering, vol. 131, no. 4, pp. 560-568, 2005.

[42] Y.-L. Pi, J. Li, H. Lu et al., “Analytical and experimental studies on out-of-plane dynamic instability of shallow circular arch based on parametric resonance," Nonlinear Dynamics, vol. 87, no. 1, pp. 677-694, 2017.

[43] J. P. Papangelis and N. S. Trahair, "Flexueal-torsional buckling tests on arches," Journal of Structural Engineering, vol. 113, no. 7, pp. 1433-1443, 1987.

[44] A.-R. Liu, Y.-H. Huang, J.-Y. Fu, Q.-C. Yu, and R. Rao, "Experimental research on stable ultimate bearing capacity of leaning-type arch rib systems," Journal of Constructional Steel Research, vol. 114, pp. 281-292, 2015.

[45] C. Dou, Y.-L. Guo, S.-Y. Zhao, and Y.-L. Pi, "Experimental investigation into flexural-Torsional ultimate resistance of Steel circular arches," Journal of Structural Engineering, vol. 141, no. 10, 2015.

[46] Y.-L. Guo, S.-Y. Zhao, Y.-L. Pi, M. A. Bradford, and C. Dou, "An experimental study on out-of-plane inelastic buckling strength of fixed steel arches," Engineering Structures, vol. 98, no. 9, pp. 118-127, 2015. 
[47] P. K. Nziu and L. M. Masu, "Cross bore geometry configuration effects on stress concentration in high-pressure vessels: a review," International Journal of Mechanical and Materials Engineering, vol. 14, no. 1, 2019.

[48] BSI, "BS EN 1999-1-1:2007- eurocode 9: design of aluminium structures- part 1-1: general structural rules," in Eurocode 9, European Committee for Standardization, Brussels, Belgium, 2007.

[49] D. Lam, T.-C. Ang, and S.-P. Chiew, Structural Steelwork Design to Limit State Theory, CRC Press, Boca Raton, FL, USA, Fouth edition, 2013.

[50] Y. J. Kang and C. H. Yoo, "Thin-walled curved beams. II: analytical solutions for buckling of arches," Journal of Engineering Mechanics, vol. 120, no. 10, pp. 2102-2125, 1994.

[51] S. C. Chapra and R. P. Canale, "Numerical methods for engineers," Mathematics and Computers in Simulation, vol. 33, no. 3, 2009.

[52] M.-Y. Kim, B.-C. Min, and M.-W. Suh, "Spatial stability of nonsymmetric thin-walled curved beams. II: numerical approach," Journal of Engineering Mechanics, vol. 126, no. 5, pp. 506-514, 2000b.

[53] N. Hu, B. Hu, B. Yan, H. Fukunaga, and H. Sekine, "Two kinds of c0-type elements for buckling analysis of thin-walled curved beams," Computer Methods in Applied Mechanics and Engineering, vol. 171, no. 1-2, pp. 87-108, 1999.

[54] T. Marwala, Finite Element Model Updating Using Computational Intelligence Techniques: Applications to Structural Dynamics, Springer Science \& Business Media, Berlin, Germany, 2010.

[55] M. Ahnlen and J. Westlund, Lateral Torsional Buckling of I-beams: A Parametric Study of Elastic Critical Moments in Strucutral Design Software, Chalmers University of Technology, Gothenburg, Sweden, 2013.

[56] J. Valeš and T. Stan, "FEM modelling of lateral-Torsional buckling using shell and solid elements," Procedia Engineering, vol. 190, pp. 464-471, 2017.

[57] D. B. La Poutré, R. C. Spoorenberg, H. H. Snijder, and J. C. D. Hoenderkamp, "Out-of-plane stability of roller bent steel arches - an experimental investigation," Journal of Constructional Steel Research, vol. 81, no. 5, pp. 20-34, 2013.

[58] Y.-L. Pi and M. A. Bradford, "Elasto-plastic buckling and postbuckling of arches subjected to a central load," Computers \& Structures, vol. 81, no. 18-19, pp. 1811-1825, 2003.

[59] Y.-L. Pi and N. S. Trahair, "Inelastic lateral buckling strength and design of steel arches," Engineering Structures, vol. 22, no. 8, pp. 993-1005, 2000.

[60] J. P. Papangelis and N. S. Trahair, "Finite element analysis of arch lateral buckling," Transactions of the Institution of Engineers of Australia, Civil Engineering, vol. 29, no. 1, pp. 34-39, 1986.

[61] Y. B. Yang, S. R. Kuo, and Y. D. Cherng, "Curved beam elements for nonlinear analysis," Journal of Engineering $\mathrm{Me}$ chanics, vol. 115, no. 4, pp. 840-855, 1989.

[62] Y.-L. Pi, M. A. Bradford, and B. Uy, "A spatially curved-beam element with warping and Wagner effects," International Journal for Numerical Methods in Engineering, vol. 63, no. 9, pp. 1342-1369, 2005.

[63] H. Lu, A. Liu, Y.-L. Pi, M. A. Bradford, and J. Fu, "Lateraltorsional buckling of arches under an arbitrary radial point load in a thermal environment incorporating shear deformations," Engineering Structures, vol. 179, pp. 189-203, 2019.

[64] J. P. Papangelis and N. S. Trahair, "Flexueal-torsional buckling tests on arches," vol. 113, no. 4, 1987.
[65] R. C. Spoorenberg, H. H. Snijder, J. C. D. Hoenderkamp, and D. Beg, "Design rules for out-of-plane stability of roller bent steel arches with FEM," Journal of Constructional Steel Research, vol. 79, pp. 9-21, 2012. 